\title{
STUDENT PERCEPTIONS OF VIDEO CONFERENCING TECHNOLOGY
}

\author{
Kevin S. Floyd, Middle Georgia State University, kevin.floyd@mga.edu \\ Neil Rigole, Middle Georgia State University, neil.rigole@mga.edu \\ Alan Stines, Middle Georgia State University, alan.stines@mga.edu
}

\begin{abstract}
Video Conferencing technologies continue to change the landscape of how academic institutions help enable learning for students. A public institution of higher education in the Southeastern United States consisting of five campuses spread out over a 150 mile geographic region has implemented many video conferencing courses throughout many disciplines in the institution to expand and diversify course offerings, reduce costs, and offer more flexibility for students. This paper aims to assess the students' perceptions of video conferencing based on their academic major on their learning experience. This research may provide insights that other institutions, faculty, and students may find helpful.
\end{abstract}

Keywords: Video Conferencing, Higher Education, Teaching Innovation

\section{INTRODUCTION}

A public university system of a large southeastern state in the United States began consolidating numerous institutions under its purview in 2012. One such newly consolidated institution (NCI) resulted from the consolidation of two former state colleges; both of which had multiple campuses. After consolidation, NCI found itself with five campuses across a 150 mile geographic region of the state. Video conferencing was suggested and invested in by the administration to extend course offerings across the region. Using video conferencing for instruction has been shown to provide benefits to institutions, instructors, and students (Hoyt, Howell, Lindeman, \& Smith, 2013; Fox, McDonough, McConatha, \& Marlowe, 2011). Synchronous video course delivery options for students would allow NCI students to take courses on their "home" campus without the necessity to commute to another campus, as well as to alleviate faculty travel between the campuses.

In the spring semester of 2014, NCI developed a pilot program for six video conferencing courses across various disciplines. These courses consisted of 15 different sections on four different campuses with a total of 167 students being taught using five different classrooms. The results of the pilot program were promising so the administration decided to expand the number of courses being offered and invest in equipping more classrooms with video conferencing technologies.

In this study, video conferencing (VCON) courses are defined as two or more physical, on-campus classrooms connected synchronously through video and audio. The instructor can decide to teach from one location all semester or can travel to different physical locations for different class periods. Currently, VCON courses are offered in five of the six academic units of the institution: College of Arts and Sciences, School of Aviation, School of Business, School of Health Sciences, and School of Information Technology. The School of Education of NCI has not yet utilized VCON for the delivery of courses across campuses.

Prior to the pilot, the pre-consolidated colleges of NCI had some existing VCON hardware in limited classrooms, but it was rarely utilized. There were two classrooms on its main campus that were in newly constructed buildings which were built with videoconferencing capabilities. These classrooms were outfitted with Cisco@/Tandberg@ $\odot$ codecs and cameras, and the institution had also invested in a Cisco Telepresence Multipoint Control Unit (MCU) for future videoconferencing needs. Post-consolidation, the university system of the state provided funding which enabled the outfitting of three additional classrooms with Cisco VCON equipment on two other NCI campuses. Due to financial 


\section{Issues in Information Systems \\ Volume 18, Issue 3, pp. 1-8, 2017}

necessity with limited funding, NCI turned to a less expensive Polycom $\odot$ solution to add an additional four classrooms across three of its campuses, and as funding continued to diminish, the solution of choice became Lifesize $\bigcirc$ cameras and codecs, which enabled NCI to continue to utilize its Cisco MCU for scheduling class sessions, but to also take advantage of cloud connectivity. As of the 2016-2017 academic year, NCI had 19 classrooms equipped for VCON course delivery. That same academic year, NCI offered 76 sections of VCON courses in the fall semester, and 70 sections of VCON courses in the spring semester across all five of its campuses. Nearly 1,500 students were enrolled in these courses during these two semesters, showing vast growth over the two years since the pilot of 15 course sections to 167 students.

This research builds upon a previous study by the researchers at the same institution which focused on the faculty perceptions of VCON course delivery (Floyd, Rigole, \& Stines, 2016). Given the increased financial investment by university administration and the growth of VCON courses at NCI to an ever increasing number of students across a variety of academic disciplines and spread over a 150 mile geographic region, the researchers sought investigate whether students view VCON as an effective method of course delivery. In addition, it is expected that students in the professional disciplines such as information technology, business, education, and business will have higher overall perceptions of the effectiveness of VCON. In a recent Educause Review article, Guidry and BrckaLorenz (2010) reported that students in professional disciplines use technology more frequently and consistently than their peers in the Arts and Sciences.

Therefore, this study will answer the following research questions:

R1: What are student perceptions of the effectiveness of using videoconferencing for course delivery?

R2: Does a student's academic major affect overall perceptions of the effectiveness of using videoconferencing for course delivery?

\section{LITERATURE REVIEW}

Technology is constantly evolving and users seem to always be looking for new things that can help make their lives and work easier. The use of video conferencing in industry is not new (Ackert and Levitt, 1987) and even today what constitutes effective practices of video conferencing is still being defined (Hoyt, Howell, Lindeman, \& Smith, 2013). The availability and diversity of video conferencing devices and faster network speeds have enabled users to have point-to-point video and audio collaboration expectedly on-demand. The geographic distances between people are becoming less and less relevant everyday as innovative communication mediums evolve.

As the technology evolves; industry (as well as higher education) must evolve with it. Higher education can only go so far to prepare students for the "real world" (Mehra, Langar, Bapna, \& Gopal, 2014). The demand for tertiary institutions to produce knowledgeable, flexible, and innovating students is greater now than ever before across many industries, yet increasing budget cuts in higher education have forced educators to find new and innovative ways to impact a greater number of students (Taylor, Nichol, \& Dziuban, 2011).

Video conferencing isn't new to higher education, yet it still continues to have a hard time being defined. As noted by Floyd, Rigole, \& Stines (2016) the "variety of devices, disciplines, configurations, vendors, and vendor-specific technical jargon make it hard for institutions to objectively evaluate video conferencing at their own institution and almost laughable when comparing video conferencing abilities with another institution" (p. 159). With all of these options, it is not always easy for faculty and support staff to choose from the myriad of instructional methods and technologies that are available (Locatis, et al., 2006; Richardson, Fox, \& Lehman, 2012). Yet while still very much an evolving technology, video conferencing has shown great promise in numerous fields of academic study, such as international collaboration in music programs (Riley, 2013), teacher education programs (Aldemir \& Ardeley, 20132104), and even pharmacy education programs (Fox, McDonough, McConatha, \& Marlowe, 2011).

Video conferencing, as an instructional delivery method, comes with both its benefits and drawbacks. Students typically rate the instructor's familiarity with the hardware/software and her/his teaching style to be the biggest indicator of success (Doggett, 2007). Other factors influence the environment as well, such as the reliability of the hardware, quality of sound and picture, and providing additional content via another means in the course (Hoyt, 


\section{Issues in Information Systems}

Volume 18, Issue 3, pp. 1-8, 2017

Howell, Lindeman, \& Smith, 2013; Fox, McDonough, McConatha, \& Marlowe, 2011). In some scenarios, such as the power being out for an entire campus, there is little that can be done at the moment to bring things online, but the instructor must still be able to open a communications medium to the disconnected location.

Video conferencing can be effective when it works; but instructors should always have additional content prepared and available to students through another means. Students can feel disconnected, uninvolved, or otherwise like they do not belong to the course even under the best of scenario (Karal, Cebi, \& Turgut, 2011; Doggett, 2007). The institution and instructor must be aware of and prepared for these scenarios. Proper training, onsite support, and supplementing content online through an online course management system can go a long way in reducing the anxiety for both instructor and student in the classroom and help improve the learning environment (Aldemir \& Ardley, 20132014).

Videoconferencing may not be a silver bullet for expanding every course's offerings. While course delivery mode may not affect a student's perception of learning (Bramorski \& Madan, 2016), great care must be taken to prepare for and execute a videoconferencing class effectively. Students must also play their part in accepting the technology and focus on learning the course material.

\section{RESEARCH METHODOLOGY}

\section{Participants}

A convenient sample consisting of students at $\mathrm{NCI}$, who were enrolled in at least one video conferencing course during the fall 2017 and spring 2017 semesters was utilized as part of this study. The sample contained students from the University's six academic units: College of Arts and Sciences, School of Aviation, School of Business, School of Health Sciences, and School of Information Technology. One hundred forty six course sections were represented. A total of 190 usable surveys were completed. Participant characteristics are shown in table 1.

\section{Instrumentation}

The instrument for this study consisted of 23 questions. Questions 1-6 were used to retrieve demographic information. Questions 7-22 used a 5-point Likert scale which ranged from (1) "strongly disagree" to (5) "strongly agree" to measure perceptions of the effectiveness of using videoconferencing for course delivery originally developed by Doggett (2007) (Appendix A). The last question was open-ended to allow students to add any additional information about their experiences with videoconferencing classes.

\section{Procedures}

The survey was administered electronically using SurveyMonkey@ ${ }^{(}$. Student e-mail addresses were retrieved from the institution's videoconferencing course rosters during fall 2017 and spring 2017 semesters, representing a total of 146 sections. An e-mail containing a hyperlink to the instrument was sent to the list of 1,459 (755 for fall 2017 and 704 for spring 2017) unduplicated and unique students. The participants were guaranteed the anonymity of responses and assured that responses would not be shared. One hundred ninety completed surveys were returned for a response rate of $13 \%$. The raw data was imported into SPSS 24 for data analysis.

\section{RESULTS}

Demographic data was collected and is presented in Table 1. Students from all of the institutions academic units were represented, College of Arts and Sciences, School of Aviation, School of Business, School of Health Sciences, and School of Information Technology. Results indicated that the majority of participants had taken only one videoconferencing class over the past year. The majority of participants were female and most students were in the 21-29 age range. Juniors represented the largest class group. 


\section{Issues in Information Systems}

Volume 18, Issue 3, pp. 1-8, 2017

Table 1. Demographic Data for Survey Respondents

\begin{tabular}{|c|c|c|}
\hline Characteristic & $\mathrm{n}$ & $\%$ \\
\hline \multicolumn{3}{|l|}{ Gender } \\
\hline Male & 80 & $42 \%$ \\
\hline Female & 108 & $57 \%$ \\
\hline Not Reported & 2 & $1 \%$ \\
\hline \multicolumn{3}{|c|}{ Number of V-Con Courses Taken Over Past Year } \\
\hline One & 80 & $42 \%$ \\
\hline Two & 45 & $24 \%$ \\
\hline More than Two & 65 & $34 \%$ \\
\hline \multicolumn{3}{|l|}{ Age Range } \\
\hline 17 or younger & 10 & $5 \%$ \\
\hline $18-20$ & 40 & $21 \%$ \\
\hline $21-29$ & 102 & $54 \%$ \\
\hline $30-39$ & 18 & $9 \%$ \\
\hline $40-49$ & 12 & $6 \%$ \\
\hline $50-59$ & 8 & $4 \%$ \\
\hline \multicolumn{3}{|l|}{ Class Year } \\
\hline Freshman & 8 & $4 \%$ \\
\hline Sophomore & 36 & $19 \%$ \\
\hline Junior & 73 & $38 \%$ \\
\hline Senior & 70 & $37 \%$ \\
\hline Unsure & 2 & $1 \%$ \\
\hline
\end{tabular}

Questions 8-23 were used to measure perceptions of VCON effectiveness. The Cronbach's alpha coefficient was calculated to test the reliability of the 15 items. The items were found to be reliable $(\alpha=.754)$. Descriptive statistics are shown in table 2 .

Table 2. Descriptive Statistics for Effectiveness of VCON for Course Delivery

\begin{tabular}{lccc}
\hline \multicolumn{1}{c}{ Student Academic Department } & $\mathrm{N}$ & $\mathrm{M}$ & $\mathrm{SD}$ \\
\hline Arts and Sciences & 64 & 3.47 & .56 \\
Aviation & 7 & 3.78 & .37 \\
Business & 80 & 3.35 & .51 \\
Health Sciences & 12 & 3.56 & .43 \\
Information Technology & 27 & 3.74 & .52 \\
\hline
\end{tabular}

To answer the research question, a one-way between subjects ANOVA was conducted to compare the effect of student's academic department of major on perceptions of the effectiveness of using videoconferencing for course delivery. Since the group sizes are unequal, violations of the assumption of homogeneity of the variance can affect the F statistic. When group sizes are not equal, the F is affected by skew, and non-normality also affects the power of F in unpredictable ways (Wilcox, 2005). To assess the homogeneity of the variance, Levene's Test was used to test the null hypothesis that the variances of the groups are the same. The variances were not significantly different at the .05 level $[\mathrm{F}(4,183)=.90, \mathrm{p}=.465]$, confirming the homogeneity of the variances among the groups.

The results of the one-way ANOVA indicated that there was a significant effect at the $\mathrm{p}<.05$ level $[\mathrm{F}(4,186)=3.73$, $\mathrm{p}=.006]$. Post hoc comparisons using the Tukey HSD test indicated that the mean video conferencing perception score for information technology students $(\mathrm{M}=3.74, \mathrm{SD}=.424)$ was significantly different than the videoconferencing perception score for business students $(\mathrm{M}=3.35, \mathrm{SD}=.509)$. No significant difference was found among students from other academic departments.

The results of the quantitative data indicate that overall, academic discipline does not affect student's perception of using videoconferencing for course delivery. Another significant finding is that on average, students across all disciplines do not have strong views of VCON technology. Students who identified themselves as majoring in a 


\section{Issues in Information Systems \\ Volume 18, Issue 3, pp. 1-8, 2017}

program within the School of Information Technology had the highest perceptions of VCON effectiveness, while students majoring in a program within the School of Business had the lowest perceptions of VCON effectiveness for course delivery.

With these results in hand, the researchers next reviewed the collection of qualitative responses from the business students. The following responses are directly related to the students' perceived effectiveness of VCON courses (R1):

- "In the future I would like an option. I took the VCON class only because it was the only option offered for the course. The (other campus) class is rarely there and when they are they completely ignore any attempt to join the discussion made by the professor. It makes for an awkward transition when the professor has to bring it back to the home location."

- "When I see video conference, I try to make sure I am on the campus with the professor. Usually the professor gets more interaction with the class that he is physically with."

- "It was glitchy. Sometimes we could barely hear what was going on on the video conference. There was a lot of time wasted trying to connect and troubleshoot problems. I understand that the university is trying to save money, but the students on the receiving end of the v-con are absolutely not benefiting from the class as they could have with a normal class. The students are not engaged at all and the professors are frustrated. This was a good idea on paper, but not practical."

- "Using VTC to instruct courses is a disservice to the students because we don't receive the same interactions with the instructors and other students. The cost of classes are the same or more and the quality of equipment is not to par. Audio and video is average and utilizing smart boards and other visual boards is limited due to static cameras. Either eliminate the VTC requirement or reduce the tuition for those courses."

- "I am not very happy with these courses because I feel that it effects my learning and ability to communicate and understand my professors. There seems to be several technical problems that occur in these classes also. I would prefer to see my professor face to face."

- "Video conferencing is terrible ineffective, and a barrier to our learning. We have students who are willing to drive the 45 minutes to (the main campus) to avoid it."

- "These classes are a joke, I have two this semester and I've been in plenty before. I have one professor this semester that alternates the classrooms and one who puts the commute room on mute the entire time. I have learned nothing from these classes except what I have taught myself or have been taught by tutor. Not to mention, this is causing me to have to be tutored for the first time in 18 years of school. I hate these classes, however; I have to take what is offered in my area due to the commute if not."

There were a couple of positive responses from the business students, including the following:

- IIn my opinion, video conference courses are a great opportunity for many students. I feel like I am engaging in a regular class during the video conferences, and I can't see the difference between learning material. In both regular and video conference classes, I am able to process material and ask for help the same way. Video conference classes allow me to work around traveling between campuses for my classes as well. By living in (another town), I will have to drive an hour one way to class beginning next spring, and if I am lucky, classes would be close in time and at the same campus. I would love if more classes would become available at the (other) campuses. This would allow me to have a more flexible schedule with life, work, and school. Overall, I love video conference class just as much as a regular in class course."

- "I think that the videoconferencing option is a great tool. For students that find it difficult to commute, videoconferencing allows us to stay on track without having to pause or figure out the commuting, especially for non-traditional students with children."

While there were comments from the information technology students as well, only two comments mentioned a preference for face-to-face sessions:

- "In-person classes will always be superior to teaching in any other form. The other forms become viable options when geographical or scheduling limitations keep traditional classrooms from happening. Every time 


\section{Issues in Information Systems}

Volume 18, Issue 3, pp. 1-8, 2017

an online or a V-Con class is created, please examine the situation very carefully and determine if an inperson classroom can be used instead."

- "I personally feel better taking a face to face class. The instructor did well in swapping his location for class. At least this way we can get some face to face instruction."

It should be noted that the majority of the students who chose to provide qualitative comments came from business students (49\%). Yet with the negative comments about their perceived effectiveness, there were several comments from the business students that showed the importance of the efforts of their professors to engage (or not engage) the students who made their courses more or less effective:

- "I am currently taking 2 VCON classes. The accounting class is working out great. The instructor knows what he is doing and continuously checks in with each class. Macroeconomics is a whole different issue. The instructor teaches the class he is in, complete with pointing to things on the board/screen that we can't see on the other campus. He speaks very fast and flips through the material so quickly that we can't take good notes or ask questions. It is very difficult to get his attention. I feel as though I am not getting enough information. Concerned about this class. He needs to slow down and acknowledge that he has other classes trying to follow what we can't see. Video conferencing is fine if the instructor understands that we are all there and listens for when we try to get his attention."

- "Horrible the instructors neglect to interact with the students on the other campus. The only teachers that have effective video conferencing courses are (name omitted) and (name omitted) as they actually took the time to prepare for a video conference course to where I did not feel neglected. Besides that I have taken numerous amounts of these stupid courses because I had no choice and they all sucked besides the two I named previously. Hire more teachers that are willing to teach in (remote campuses) if you guys are going to have all these campuses if not then only have a (home) Campus because those are the only students who can actually interact with their teachers in every class they decide to take."

- "The professor I had had no idea how to do anything that involved a computer. This professor is so scatterbrained that the conference calls only made it worse, to the point that $80 \%$ of the class would get up and leave after 15 minutes when he was on conference call. Would not recommend. Horrible experience."

\section{Limitations}

The results of this study suffer from the limitation of small sample size and possibly biased participation. A convenience sample of students taking at least one VCON course at a single university was utilized, which many not be representative of the larger population. Another limitation is the survey developed by Doggett (2007). At the time of this study, no prior research has been conducted to assess the construct validity of the instrument. Future analysis is needed to confirm the construct validity of the survey.

\section{SUMMARY AND FURTHER RESEARCH}

In regards to research question one, the results of this study found that on average, students across all disciplines do not have strong views of VCON technology. Students who identified themselves as majoring in a program within the School of Information Technology had the highest perceptions of VCON effectiveness, while students majoring in a program within the School of Business had the lowest perceptions of VCON effectiveness for course delivery.

In terms of the second research question, results indicated that the academic discipline did affect the overall perception of using videoconferencing for course delivery. A significant difference between the mean video conferencing perception score was found only between business students and information technology students.

The qualitative data show that business students overwhelming complained about the effectiveness of their VCON classes (as compared to the non-business and information technology student response data). This leads the researchers to the question as to what other variables could be responsible for this difference. Do students who major in business have expectations beyond those of other academic areas related to course delivery quality? Are there characteristics of students majoring in business that are different from other majors, in particular information technology students? 


\section{Issues in Information Systems \\ Volume 18, Issue 3, pp. 1-8, 2017}

Are there characteristics of business courses and faculty at NCI that would impact the students' video conferencing perspective? Are there characteristics of information technology students that allow them to be more adaptable to technological problems in the course delivery as compared to other non-information technology students?

Video conferencing can be a positive experience for students if the conditions are conducive to learning. Instructors, in an attempt to understand more about preparing course pedagogy, could find these results to be quite useful. For example, making sure to include remote students in discussions, lectures, and content can go a long way in making sure these students are engaged in the course and do well. Providing alternative means of content via a Learning Management System may help reduce student anxiety about missing the key content during the video conferencing format. Perceptions of the instructor can directly influence the perceptions of their students so an instructor must be willing and enthusiastic about using it. Academics in administration can see a heavy focus on the quality of audio, availability of support technicians, reliability, and the need to be able to commit resources in very short timeframes. For everyone, communication is the biggest key to success. Students must be able to communicate with their instructors and instructors with administrative personnel to make sure everything runs very smoothly each and every time.

The qualitative data do confirm the results of Doggett (2007) that according to the perspectives of students, the teacher is a strong indicator of the perceived effectiveness VCON course. Even given problems, faculty can impact a students' satisfaction with their course. Further research could inform if there are significant differences in how business teachers at NCI deliver courses via VCON as compared with non-business faculty, in particular how information technology teachers teach via VCON.

\section{REFERENCES}

Acker, S. R., \& Levitt, S. R. (1987). Designing Videoconference Facilities for Improved Eye Contact. Journal of Broadcasting and Electronic Media, 31(2), 181-191.

Aldemir, J., \& Ardley, J. (2013-2014). Utilizing Videoconferencing Technology to Instruct Remote Non-Traditional Teacher Education Students. Educational Technology Systems, 42(4), 383-403.

Bramorski, T., \& Madan, M. S. (2016). Evaluating Student Perceptions of Course Delivery Platforms. Journal of College Teaching \& Learning, 13(2), 29-35.

Doggett, M. A. (2007). The Video Conferencing Classroom: What Do Students Think? Journal of Industrial Teacher Education, 44(4), 29-41.

Floyd, K., Rigole, N., \& Stines, A. (2016). Faculty Perceptions of Video Conferencing Technology. Issues in Information Systems, 17(4), 158-166.

Fox, B. I., McDonough, S. L., McConatha, B. J., \& Marlowe, K. F. (2011). Establishing and Maintaining a Satellite Campus Connected by Synchronous Video Conferencing. American Journal of Pharmaceutical Education, 75-80.

Guidry, K.R., \& BrckaLorenz, A. (2010). A comparison of student and faculty academic technology use across disciplines. EDUCAUSE review. Boulder, CO :EDUCAUSE

Hoyt, J. E., Howell, S. L., Lindeman, S., \& Smith, M. (2013). The Feasbility of Offering Videoconferencing Courses: Quality Issues and Lessons Learned. The Journal of Higher Education, 61, 94-103.

Karal, H., Çebi, A., \& Turgut, Y. E. (2011). Perceptions of Students Who Take Synchronous Courses Through Video Conferencing About Distance Education. Turkish Online Journal of Educational Technology, 10(4), 276-293. 
Mehra, A., Langer, N., Bapna, R., \& Gopal, R. (2014). Estimating Return to Training in the Knowledge Economy: A Firm-Level Analysis of Small and Medium Enterprises. MIS Quarterly, 38(3), 757-771.

Riley, P. (2013). Video-Conferenced Classes: American Pre-Service Music Educators Teach Composition Skills to Students in Japan. Journal of Technology in Music Learning, 5(1), 51-69.

Shephard, K., \& Knightbridge, K. (2011). Exploring Presentation Styles in Higher Education Teaching and Research Situations: distance and face-to-face. Open Learning, 26(3), 223-236.

Wilcox, R.R. (2005). Introduction to robust estimation and hypothesis testing, $2^{\text {nd }}$ ed. Burlington, MA: Elsevier.

\section{APPENDIX A}

\section{STUDENT PERCEPTIONS OF VIDEO CONFERENCING COURSE DELIVERY SURVEY}

[Q1] If you are willing to participate, signify by clicking the Yes button below.

[Q2] How many video conferenced courses are you currently taking or have taken in the past?

\section{Demographics}

[Q3] What is your age?

[Q4] What is your age?

[Q5] What is your class year?

[Q6] What is the academic department of your major or intended major?

[Q7] What is the academic department of the video conference course you are taking currently?

\section{Student Questions}

[Q8] I am comfortable asking questions using the videoconferencing format.

[Q9] I would have felt more engaged in a normal class setting.

[Q10] The videoconferencing technology is a barrier to my interaction with the instructor.

[Q11] The purpose of using the videoconferencing technology is clear to me.

[Q12] The instructor uses videoconferencing technology appropriately.

[Q13] The instructor appears confident in using the videoconferencing technology.

[Q14] The instructor uses appropriate media with the videoconferencing to enhance learning.

[Q15] The use of videoconferencing technology in this course encourages me to continue discussions.

[Q16] The use of videoconferencing technology in this course encourages me to learn independently.

[Q17] The instructor encourages me to ask questions.

[Q18] The instructor establishes rapport with participants.

[Q19] The instructor is able to facilitate our communication.

[Q20] If I knew this was going to be a videoconferencing class, I would not have taken it.

[Q21] The instructor is able to use the videoconferencing technology required for this course.

[Q22] I would take another course that used this technology.

[Q23] I would recommend this course using this technology.

[Q24] Anything else you would like to add? 